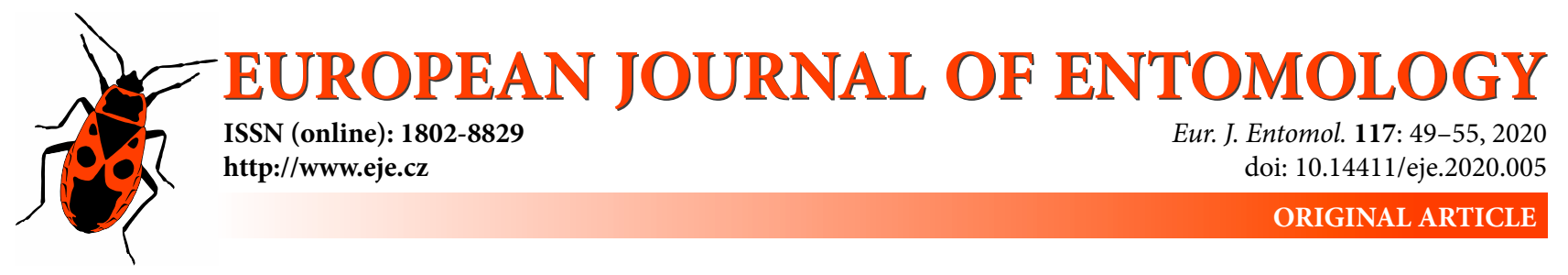

\title{
Functional responses of two predatory bugs (Hemiptera: Anthocoridae) to changes in the abundance of Tetranychus urticae (Acari: Tetranychidae) and Bemisia tabaci (Hemiptera: Aleyrodidae)
}

\author{
Serkan Pehlivan, Tuğcan Alinç, Tange Denis ACHIRI and Ekrem ATAKaN \\ Department of Plant Protection, Agricultural Faculty, University of Çukurova, Adana, Turkey; e-mails: spehlivan@cu.edu.tr, \\ alinctugcan@gmail.com, achiritange@gmail.com, eatakan@mail.cu.edu.tr
}

Key words. Anthocoridae, Orius spp., biological control, functional response, prey abundance, Tetranychus urticae, red spider mite, Bemisia tabaci, whitefly

\begin{abstract}
Orius spp. (Hemiptera: Anthocoridae) is well-known genus of generalist predators, which feed on numerous pest insects and mites infesting crops. In this study, the functional responses of the predatory bugs, Orius laevigatus (Fieber) and Orius vicinus (Ribaut), to different densities of the eggs of the whitefly, Bemisia tabaci (Gennadius) (Hemiptera: Aleyrodidae) and red spider mite, Tetranychus urticae Koch (Acari: Tetranychidae), were determined under laboratory conditions. Different numbers of eggs $(2,4,6,8,16,32,64$ and 128) of both species of prey were offered to females of the above predators for 24-h in a controlled environment of $25 \pm 1{ }^{\circ} \mathrm{C}, 60 \pm 10 \% \mathrm{RH}$ and under a $16 \mathrm{~L}: 8 \mathrm{D}$ photoperiod. The parameters of the functional responses were assessed using Holling's Disc Equation. Both predators showed a Type II response to both prey. The attack rates (a) and handling times (Th) of the predators were computed for spider mites eggs: O. laevigatus (a: 0.972 , Th: 0.007 ) and O. vicinus (a: 1.113 , Th: 0.005), and whitefly eggs: O. laevigatus (a: 1.022 , Th: 0.002 ) and 0 . vicinus (a: 0.772 Th: 0.006 ). Furthermore, the average number of $B$. tabaci eggs consumed by $O$. laevigatus females was greater than by those of $O$. vicinus. In contrast, $O$. vicinus was a more efficient predator of $T$. urticae eggs than O. laevigatus. Consequently, these results indicate that together these predators might be effective biological control agents in regulating populations of $B$. tabaci and $T$. urticae in agricultural ecosystems.
\end{abstract}

\section{INTRODUCTION}

The cotton whitefly, Bemisia tabaci (Gennadius) (Hemiptera: Aleyrodidae) and the two-spotted spider mite, Tetranychus urticae Koch (Acari: Tetranychidae) are common phytophagous pests that damage many economically important agricultural crops around the world (Jeppson et al., 1975; Helle \& Sabelis, 1985; Gerling et al., 2001; Aslan et al., 2004). Bemisia tabaci causes direct and indirect damage by sucking sap, virus transmission and producing honeydew that leads to rapid growth of sooty mould (Breene et al., 1992). Tetranychus urticae feeds on leaves causing damage to chlorophyll and thereafter serious loss of yield (Nachman \& Zemek, 2002). For the control of these pests, farmers mostly apply chemical treatments to keep their abundance below economic damage threshold levels (Knowles, 1997; Denholm et al., 1998; Van Leeuwen et al., 2010). However, intensive use of pesticides adversely affects the environment and human health. Moreover, it becomes ineffective due to resistance that is developed by the pest after a while and in restricting naturally occurring biological control agents (Riudavets \& Castañé, 1998; Biondi et al., 2012). Therefore, alternative pest control strategies including biological control have been adopted to control whiteflies and spider mites around the world in recent years (Lester et al., 2000; Bostanian et al., 2003; Roy et al., 2005; Calvo et al., 2009; Drobnjaković et al., 2016).

To date, several studies report that whiteflies and spider mites have many predators and parasitoids belonging to various families, e.g., Aphelinidae, Phytoseidae, Miridae, Thripidae, Anthocoridae (Lopez-Avila, 1986; Raworth, 1990; Cote, 2001; Gerling et al., 2001; Gigon et al., 2016). Among them, Anthocoridae (Hemiptera: Cimicoidea), which include a number of genera (e.g., Anthocoris, Orius), are well-known as generalist predators, preying upon small bodied insects such as thrips, whiteflies, mites, scales, aphids, psyllids, psocids, bark beetles, small caterpillars and the eggs of various insects and mites (Önder, 1982; Lattin, 2002). According to field observations on species of anthocorids in Adana province of Turkey, Orius laevigatus (Fieber) and $O$. vicinus Ribaut are the most common species, followed by $O$. niger Wolff (Pehlivan \& Atakan, 2020). While $O$. laevigatus has been commercially used for the biological control of the thrips Frankliniella occidentalis (Pergande) (Thysanoptera: Thripidae) in Mediterranean regions (Chambers et al., 1993), O. vicinus is considered to be a potential biological control agent against 
various species of thrips and especially phytophagous mites (Heitmans et al., 1986). There are several studies on the biological parameters and predation abilities of these predators feeding on different prey (Alvarado et al., 1997; Cocuzza et al., 1997; Wearing \& Colhoun, 1999; Pehlivan \& Atakan, 2017). However, there is little knowledge of their efficiency as predators of B. tabaci and T. urticae with the view of using them as biological control agents (Venzon et al., 2002; Arnó et al., 2008).

Their efficiency in regulating pest populations depends on different biological and behavioural traits. One of the most important methods for evaluating their effectiveness in biological control programs is to determine their response to changes in prey species and densities, namely, their functional responses (Rogers, 1972; Houck \& Strauss, 1985). Holling (1965) identified three types of functional response: (i) increasing linear response to increasing prey density, type I response, (ii) initial linear response that reaches a plateau, type II response, and (iii) sigmoidal shaped response with a slow start, type III response. There are functional response studies on anthocorid bugs to some stages of pests indicate that a type II response is the most often recorded for species of Orius (Coll \& Ridgway, 1995; Alvarado et al., 1997; Montserrat et al., 2000; Rutledge \& O'Neil, 2005). However, there is no data on the functional responses of $O$. laevigatus and $O$. vicinus to different egg densities of B. tabaci and T. urticae.

The aim of this study was to determine the functional response of two species of anthocorids to different egg densities $(2,4,6,8,16,32,64$ and 128) of two species of prey over a $24 \mathrm{~h}$ period under laboratory conditions. The following topics were addressed: (1) Do the predators in same genus show different types of functional response when feeding on the same prey? (2) How does the functional response of each predator change when they feed on different prey? (3) What is their potential for suppressing pest populations in biological control programs? The results and further investigations might be helpful in estimating the predatory ability of $O$. laevigatus and $O$. vicinus when attacking B. tabaci and T. urticae and their value as biological control agents.

\section{MATERIAL AND METHODS}

\section{Insect rearing}

Cultures of the predators $O$. vicinus and $O$. laevigatus were established in the Laboratory of Entomology (hereafter referred as laboratory) of Cukurova University, Adana, Turkey. These predators were collected from pepper and eggplant crops grown in open fields in the Adana Province, Turkey in 2016. The predators were identified using the identification key of Péricart (1972) and later reared separately in plastic jars (1 1) with a perforated lid $(5 \mathrm{~cm}$ diameter) and sealed with mesh cloth for ventilation and preventing escape, respectively. Adults and nymphs of these predatory bugs were fed (ad libitum) with frozen eggs of the Mediterranean flour moth, Ephestia kuehniella Zeller (Lepidoptera: Pyralidae) and pollen of Typha latifolia L. (Typhaceae). The moth culture was obtained from the Biological Control Research Institute in Adana in 2016 and maintained in the laboratory. Bean pods of Phaseolus vulgaris L. were provided every other day as a substrate for oviposition. The bean pods were replaced with fresh ones every two days and the old pods (after oviposition) were transferred to new containers to start a new generation. The predators were reared in a climatic chamber (Nüve TK120) at $25 \pm 2{ }^{\circ} \mathrm{C}, 65 \pm 5 \mathrm{RH} \%$ and under a photoperiod of $14 \mathrm{~L}: 10 \mathrm{D}$.

Nymphs and adults of B. tabaci reared on cotton plants in a controlled room (at $25 \pm 2{ }^{\circ} \mathrm{C}, 65 \pm 5 \mathrm{RH} \%$, photoperiod of $14 \mathrm{~L}$ : 10D) in the Department of Plant Protection were used. This culture of $B$. tabaci was maintained for about 5 years, and twice a year field collected $B$. tabaci were added to the culture in order to prevent genetic degeneration.

Adults of the red spider mite, T. urticae were collected from pesticide-free strawberry in a semi greenhouse in the Agricultural Research and Implementation Area of Cukurova University, Adana, Turkey. These mites were reared on potted bean plants in wooden-framed mesh cloth cages $(1 \mathrm{~m} \times 1 \mathrm{~m} \times 1 \mathrm{~m})$. Potted bean plants in the cages were replaced when necessary. The cages were kept in a controlled room $\left(25 \pm 2{ }^{\circ} \mathrm{C}, 65 \pm 5 \mathrm{RH} \%, 14 \mathrm{~L}: 10 \mathrm{D}\right.$ photoperiod). Tetranychus urticae culture has been maintained in the laboratory for two years.

\section{Functional response experiments}

Cups $(5 \mathrm{~cm} \times 2 \mathrm{~cm})$ were used as experimental units. Fresh bean (Phaseolus vulgaris L.) leaf discs ( $2.5 \mathrm{~cm}$ diameter) were placed upside down on wet cotton in the bottom of cups to keep the leaf disc fresh. To ensure maximum predation rates the numbers of eggs of the prey provided were determined in a preliminary experiment. With a fine camel's hair brush and under a stereomicroscope (Olympus SZ51) (X40), 2, 4, 8, 16, 32, 64 and 128 eggs of both species of prey were transferred onto the leaf discs in separate cups. Within five minutes of transferring the prey, a one-day-old female predator, which had been starved for $24 \mathrm{~h}$ was placed on the leaf disc in the each cup. The cups were covered with a perforated $(2 \mathrm{~cm})$ lid and sealed with a mesh cloth. The cups were randomly placed in the rearing chamber and kept at 25 $\pm 2^{\circ} \mathrm{C}, 65 \pm 5 \mathrm{RH} \%$ and under a photoperiod of $14 \mathrm{~L}: 10 \mathrm{D}$. There were between 10-15 replicates per treatment (prey-predator). In total, there were 4 treatments (prey-predator); (i): T. urticae - $O$. laevigatus, (ii): T. urticae - O. vicinus, (iii): B. tabaci-O. laevigatus and (iv): B. tabaci-O. vicinus. Twenty-four hours later, the number of eggs consumed $(\mathrm{Na})$ were counted with the aid of a stereomicroscope (X40).

\section{Data analyses}

t-test

An independent t-test was used to evaluate differences in the number of eggs consumed by $O$. laevigatus and $O$. vicinus at each egg density. The analyses were done using the statistical Package Social Science SPSS (IBM Corp., 2015).

\section{Functional response analyses}

A logistic regression equation was used to determine the shape of the functional response recorded in each prey-predator interaction. The logistic regression model is suitable for these analyses since the output variable is dichotomous (consumed or unconsumed). In addition, the distribution of the error terms of this variable is often binomial rather than normal (Trexler et al., 1988). This logistic regression equation (1) determined the proportion of prey consumed $(\mathrm{Na} / \mathrm{No})$ as a function of the initial prey density (No) (Juliano, 2001).

$$
\frac{N_{a}}{N_{0}}=\frac{\exp \left(P_{0}+P_{1} N_{0}^{1}+P_{2} N_{0}^{2}+P_{3} N_{0}^{3}\right)}{1+\exp \left(P_{0}+P_{1} N_{0}^{1}+P_{2} N_{0}^{2}+P_{3} N_{0}^{3}\right)}
$$

The maximum likelihood test was used to estimate the parameters $\mathrm{P}_{0}, \mathrm{P}_{1}, \mathrm{P}_{2}$, and $\mathrm{P}_{3}$, which are the intercept, linear, quadratic 
and cubic coefficients, respectively. According to Juliano (2001), if the linear term $\left(\mathrm{P}_{1}\right)$ is not significantly different from zero, it indicates a type I functional response. Also, if $\mathrm{P}_{1}$ is significant $<0$, this implies that the proportion of prey consumed declines monotonically with $\mathrm{N}_{0}$ indicating a type II functional response. On the other hand, if $\mathrm{P}_{1}$ is significant $>0$, then the proportion of prey consumed is positively density-dependent, hence a type III function response.

Knowing the shapes of the functional response curves of the predators, the next step was to determine the parameters of Holling's disc equation (2). This equation is suitable for estimating the predator attack rate or instantaneous searching rate (a) and the handling time $\left(\mathrm{T}_{h}\right)$ since the initial egg densities of prey were depleted without replacement (Rogers, 1972). A nonlinear least square regression (NLIN procedure in SPSS ver. 23) was used to estimate these parameters.

$$
N_{a}=\frac{a T N_{0}}{1+a T_{h} N_{0}} \text { (2) }
$$

Where $\mathrm{N}_{\mathrm{a}}$ is the number of eggs consumed, $\mathrm{N}_{0}$ is the initial density of eggs, a is the predator attack rate or instantaneous searching rate, $\mathrm{T}$ is the time of exposure of predator to prey $(\mathrm{T}=$ $24 \mathrm{~h}$ ) and $T_{h}$ is the handling time. It is worth noting that since all functional response curves were type II, no adjustments to equation 2 were necessary in order to estimate the parameters for type III prey-predator functional response curves.

\section{RESULTS}

The results obtained from the logistic regression analysis of the functional response experiments had significantly negative $\mathrm{P}_{1}$ values indicating that the functional responses of both species of Orius to different densities of the eggs of T. urticae and B. tabaci were of type II (Table 1). The proportion of eggs of $T$. urticae and $B$. tabaci consumed by each predator declined and plateaued above a density of 64 eggs (Fig. 1).

Following the determination of the Type II functional responses, attack rate (a) and handling time $\left(\mathrm{T}_{\mathrm{h}}\right)$ of Orius spp. were estimated using Holling's Disc Equation (Holling, 1959). The attack rates of $O$. laevigatus, when fed eggs of T. urticae and B. tabaci were $0.972 \pm 0.073 \mathrm{~h}^{-1}$ and

Table 1. Maximum-likelihood estimates based on the logistic regressions of the proportion of Tetranychus urticae and Bemisia tabaci eggs eaten by Orius laevigatus and Orius vicinus at different initial densities of prey.

\begin{tabular}{|c|c|c|c|c|c|c|}
\hline Predator & Prey & Coefficients & Estimates & S.E. & $x^{2}$ & $p$-value \\
\hline \multirow[b]{2}{*}{ O. laevigatus } & $\begin{array}{c}T . \\
\text { urticae }\end{array}$ & $\begin{array}{c}\text { Intercept } \\
\text { Linear } \\
\text { Quadratic }\end{array}$ & $\begin{array}{c}-0.914 \\
-0.021 \\
0.00\end{array}$ & $\begin{array}{l}0.153 \\
0.006 \\
0.00\end{array}$ & $\begin{array}{l}35.42 \\
14.133 \\
25.45\end{array}$ & $\begin{array}{l}<0.0001 \\
<0.0001 \\
<0.0001\end{array}$ \\
\hline & $\begin{array}{c}B . \\
\text { tabaci }\end{array}$ & $\begin{array}{l}\text { Intercept } \\
\text { Linear } \\
\text { Quadratic } \\
\text { Cubic }\end{array}$ & $\begin{array}{c}-0.758 \\
-0.033 \\
0.00 \\
0.00\end{array}$ & $\begin{array}{l}0.264 \\
0.022 \\
0.00 \\
0.00 \\
\end{array}$ & $\begin{array}{l}8.228 \\
2.422 \\
1.242 \\
0.400\end{array}$ & $\begin{array}{l}0.004 \\
0.020 \\
0.265 \\
0.527\end{array}$ \\
\hline \multirow{2}{*}{ O. vicinus } & $\begin{array}{c}T . \\
\text { urticae }\end{array}$ & $\begin{array}{l}\text { Intercept } \\
\text { Linear } \\
\text { Quadratic } \\
\text { Cubic }\end{array}$ & $\begin{array}{c}-0.271 \\
-0.127 \\
0.002 \\
0.00\end{array}$ & $\begin{array}{l}0.277 \\
0.025 \\
0.00 \\
0.00 \\
\end{array}$ & $\begin{array}{r}0.96 \\
25.66 \\
22.21 \\
17.99 \\
\end{array}$ & $\begin{array}{c}0.329 \\
<0.0001 \\
<0.0001 \\
<0.0001\end{array}$ \\
\hline & $\begin{array}{c}B . \\
\text { tabaci }\end{array}$ & $\begin{array}{l}\text { Intercept } \\
\text { Linear } \\
\text { Quadratic } \\
\text { Cubic }\end{array}$ & $\begin{array}{r}0.428 \\
-0.138 \\
0.003 \\
0.00\end{array}$ & $\begin{array}{l}0.243 \\
0.021 \\
0.00 \\
0.00\end{array}$ & $\begin{array}{r}3.09 \\
45.14 \\
47.87 \\
47.18\end{array}$ & $\begin{aligned} & 0.078 \\
< & 0.0001 \\
< & 0.0001 \\
< & 0.0001\end{aligned}$ \\
\hline
\end{tabular}

$1.022 \pm 0.085 \mathrm{~h}^{-1}$, respectively, and the handling times $\left(\mathrm{T}_{\mathrm{h}}\right)$ were $0.007 \pm 0.001 \mathrm{~h}$ and $0.002 \pm 0.001 \mathrm{~h}$, respectively. For $O$. vicinus, the attack rates were $1.113 \pm 0.083 \mathrm{~h}^{-1}$ on T. urticae and $0.772 \pm 0.147 \mathrm{~h}^{-1}$ on $\mathrm{B}$. tabaci and handling times $\left(\mathrm{T}_{\mathrm{h}}\right)$ of $O$. vicinus were $0.005 \pm 0.001 \mathrm{~h}$ and $0.006 \pm$ $0.002 \mathrm{~h}$, respectively (Table 2 ).

The mean number of eggs of T. urticae and B. tabaci consumed at different densities by the Orius spp. is given on Table 3. The number eggs of T. urticae eaten by predators increased and reached a plateau, and there were statistical differences in numbers eaten by the two species of Orius spp. at egg densities 2 and 32. For B. tabaci eggs, each predator consumed more eggs at higher densities and generally $O$. laevigatus and $O$. vicinus consumed similar numbers of eggs at each of the densities (except 4 eggs). Our findings indicate that predators are not able to consume an infinite number of prey as prey density increases. Consequently, beyond a certain level of prey abundance more predators will be required to keep prey numbers below the economic threshold level.

\section{DISCUSSION}

Many predators that have been successfully used as biocontrol agents for important pests in greenhouses exhibit a type II response to their prey (Pervez \& Omkar, 2006; Xiao \& Fadamiro, 2010). Our results clearly indicate that the functional responses of $O$. laevigatus and $O$. vicinus to different densities of the eggs of T. urticae and B. tabaci are of type II. There is no study on the functional response of $O$. vicinus in the literature to the best of our knowledge. Monsterrat et al. (2000) report that $O$. laevigatus exhibits Type II responses when fed nymphs of $T$. vaporariorum and $F$. occidentalis. In the literature, there are many studies on different species of Orius preying on greenhouse pests, which report type II functional responses. For instance, O. niger and Orius minutus (L.) exhibit type II functional responses when fed adults of $T$. urticae and 2 nd instar individuals of the onion thrips, Thrips tabaci Lindeman (Thysanoptera: Thripidae) (Fathi \& Nouri-Ganbalani, 2010), Orius albidipennis (Reuter) fed eggs and 3rd instar nymphs of $B$. tabaci (Shahpouri et al., 2019), Orius sauteri (Poppius) fed adults of Megalurothrips usitatus (Bagnall) (Thysanoptera: Thripidae) (Liu et al., 2018), O. albidipennis fed adults of Megalurothrips sjostedji Trybom (Thysanoptera: Thripi-

Table 2. Estimated (mean \pm SE) attack rates (a) and handling times (Th) of females of Orius laevigatus and Orius vicinus of eggs of Tetranychus urticae and Bemisia tabaci.

\begin{tabular}{|c|c|c|c|c|c|c|}
\hline \multirow{2}{*}{ Predator } & \multirow{2}{*}{ Prey } & \multirow{2}{*}{$\begin{array}{l}\text { Para- } \\
\text { meters }\end{array}$} & \multirow{2}{*}{$\begin{array}{l}\text { Estimate } \\
\pm \mathrm{SE}\end{array}$} & \multicolumn{2}{|c|}{ Asymptotic $95 \% \mathrm{Cl}$} & \multirow{2}{*}{$\mathrm{R}^{2}$} \\
\hline & & & & Lower & Upper & \\
\hline \multirow{3}{*}{ O. laevigatus } & & $a$ & 0.97 & 0. & & \multirow{2}{*}{0.90} \\
\hline & urtice & $T_{h}$ & 0.00 & 0.005 & 0.008 & \\
\hline & $\begin{array}{c}B . \\
\text { tabaci }\end{array}$ & $\begin{array}{l}\mathrm{a} \\
\mathrm{T}_{\mathrm{h}}\end{array}$ & $\begin{array}{l}1.022 \pm 0.085 \\
0.002 \pm 0.001\end{array}$ & $\begin{array}{l}0.806 \\
0.001\end{array}$ & $\begin{array}{l}1.239 \\
0.006\end{array}$ & 0.88 \\
\hline \multirow{2}{*}{ O. vicinus } & $\begin{array}{c}T . \\
\text { urticae }\end{array}$ & $\begin{array}{l}\mathrm{a} \\
\mathrm{T}_{\mathrm{h}}\end{array}$ & $\begin{array}{l}1.113 \pm 0.083 \\
0.005 \pm 0.001\end{array}$ & $\begin{array}{l}0.917 \\
0.003\end{array}$ & $\begin{array}{l}1.310 \\
0.007\end{array}$ & 0.925 \\
\hline & $\begin{array}{c}B . \\
\text { tabaci }\end{array}$ & $\begin{array}{l}\mathrm{a} \\
\mathrm{T}_{\mathrm{h}}\end{array}$ & $\begin{array}{l}0.772 \pm 0.147 \\
0.006 \pm 0.002\end{array}$ & $\begin{array}{l}0.540 \\
0.004\end{array}$ & $\begin{array}{l}1.003 \\
0.009\end{array}$ & .78 \\
\hline
\end{tabular}



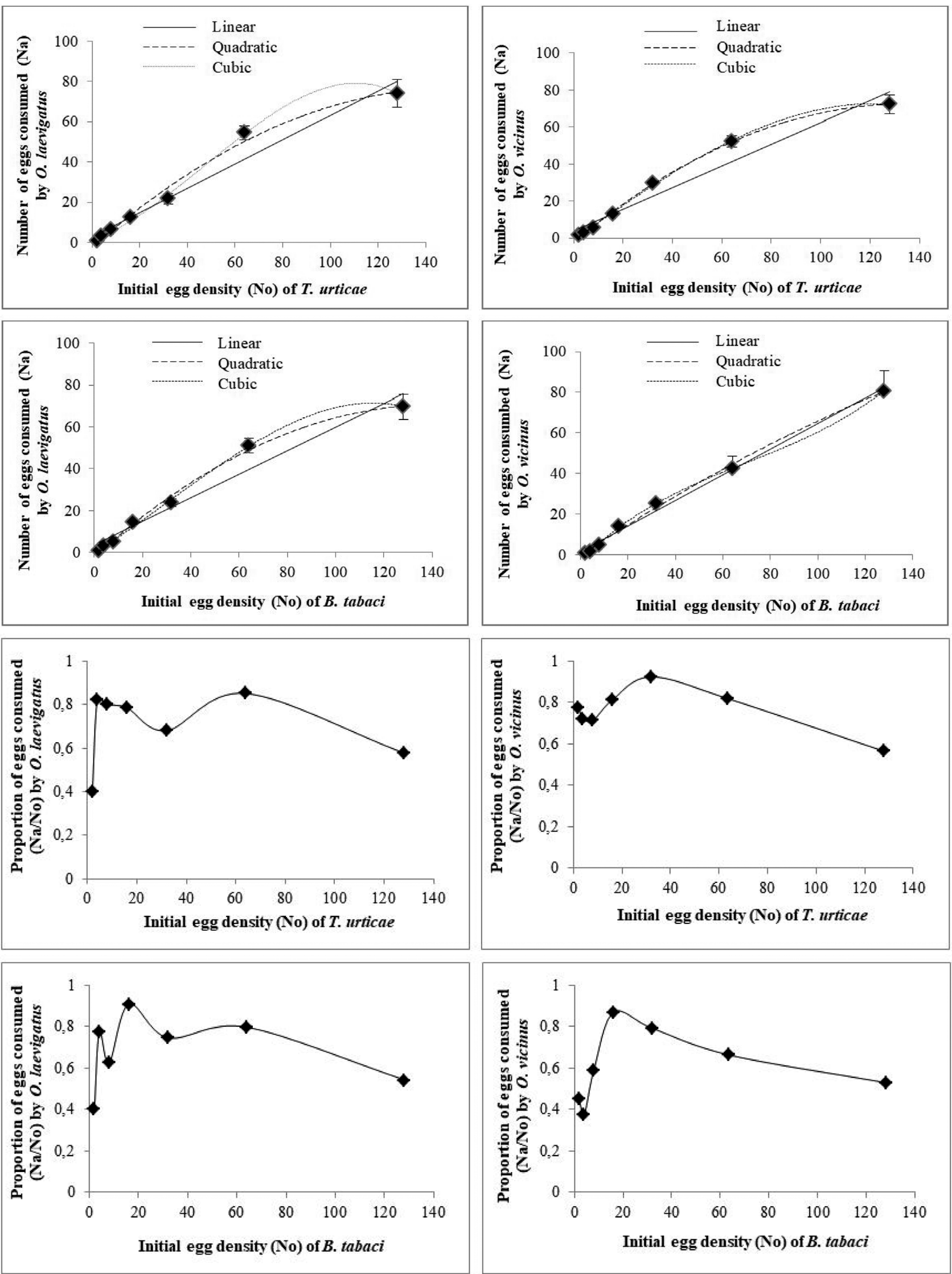

Fig. 1. Type II Functional responses and proportion of eggs consumed by Orius laevigatus and Orius vicinus when provided with different densities of the eggs of Tetranychus urticae and Bemisia tabaci.

dae) (Gitonga et al., 2002) and Orius tristicolor (White) fed eggs of Tuta absoluta Meyrick (Lepidoptera: Gelechii- dae) (Queiroz et al., 2015). In contrast, O. albidipennis and Orius strigicollis (Poppius) fed eggs of T. urticae (Jalali- 
Table 3. Mean ( \pm SE) numbers of eggs of Tetranychus urticae and Bemisia tabaci consumed by Orius laevigatus and Orius vicinus.

\begin{tabular}{lcccrc}
\hline Prey & $\begin{array}{c}\text { Density } \\
\text { (No.) }\end{array}$ & O. laevigatus & O. vicinus & $\begin{array}{r}\text { t-test } \\
\text { value }\end{array}$ & $P$ values \\
\hline & 2 & $0.80 \pm 0.30$ & $1.55 \pm 0.158$ & -2.118 & 0.048 \\
& 4 & $3.29 \pm 0.24$ & $2.89 \pm 0.47$ & 0.808 & 0.428 \\
& 8 & $6.40 \pm 0.38$ & $5.70 \pm 0.71$ & 0.958 & 0.348 \\
T. urticae & 16 & $12.58 \pm 0.83$ & $13.0 \pm 0.94$ & -0.325 & 0.748 \\
& 32 & $21.78 \pm 2.58$ & $29.60 \pm 1.07$ & -2.819 & 0.012 \\
& 64 & $54.50 \pm 3.19$ & $52.38 \pm 3.17$ & 0.457 & 0.654 \\
& 128 & $74.00 \pm 6.71$ & $72.30 \pm 5.11$ & 0.200 & 0.844 \\
\hline B. tabaci & 16 & $14.55 \pm 0.51$ & $13.91 \pm 0.49$ & 0.864 & 0.398 \\
& 2 & $0.80 \pm 0.24$ & $0.90 \pm 0.23$ & -0.293 & 0.773 \\
& 4 & $3.10 \pm 0.26$ & $1.50 \pm 0.36$ & 3.446 & 0.003 \\
& 64 & $51.10 \pm 3.54$ & $42.42 \pm 6.14$ & 1.155 & 0.262 \\
& 128 & $69.60 \pm 5.95$ & $70.07 \pm 9.69$ & -0.969 & 0.345 \\
\hline
\end{tabular}

zand et al., 2012; Tuan et al., 2016) and O. albidipennis fed eggs of T. absoluta (Salehi et al., 2016) exhibit type III functional responses. This may be a consequence of using different species of prey, or Orius, or host plants in these studies. In addition, Jalalizand et al. (2012) report that $O$. albidipennis shows a type III functional response when fed T. urticae eggs, but these authors used two different host plants, strawberry and cucumber, which could affect predator foraging behaviour. Furthermore, when T. absoluta eggs are provided to two different species of Orius, O. tristicolor and O. albidipennis, they exhibit type II and type III functional responses, respectively (Queiroz et al., 2015; Salehi et al., 2016).

Predators with high attack rates (a) and low handling times $\left(T_{h}\right)$ are considered to be more efficient biological control agents of pests (Fathi \& Nouri-Ganbalani, 2010; Salehi et al., 2016). Our results indicate that $O$. laevigatus is more effective than $O$. vicinus in terms of the number of eggs of $B$. tabaci eaten, whereas $O$. vicinus had a higher predation rate when fed eggs of T. urticae. According to Heitmans et al. (1986) O. vicinus is considered to be a potential biological control agent of phytophagous mites. In addition, some researchers report that $O$. laevigatus prefers mixed stages of T. urticae and B. tabaci to species of thrips (Venzon et al., 2002; Arnó et al., 2008). This could be due the mites and whiteflies having stages (e.g. eggs, larvae or nymphs) that are more vulnerable to attack by predators. When prey are immobile, such as eggs or pupae, the predation rates can be high under natural field conditions (Andow, 1990; Cook et al., 1996). In this study, the mean consumption rates of $O$. vicinus were higher than $O$. laevigatus at eggs densities of T. urticae of 2 and 32, whereas $O$. laevigatus consumed more $B$. tabaci eggs when provided with 4 eggs. Tuan et al. (2016) report that $O$. strigicollis show similar consumption rates of $T$. urticae eggs at the highest densities. In contrast, $O$. albidipennis consume fewer T. urticae (Jalalizand et al., 2012) and B. tabaci eggs (Shahpouri et al., 2019). The differences may be due to the different morphologies of the host plants. Many authors indicate that plant morphology, such as leaf hairs and trichome density, greatly affect the searching ability of preda- tors (De Clercq et al., 2000; Cedola et al., 2001; Madadi et al., 2007; Jalalizand et al., 2012; Banihashemi et al., 2017).

In conclusion, this is the first report of the functional responses of $O$. laevigatus and $O$. vicinus to the abundance of two important species of pests, B. tabaci and T. urticae. In Turkey, the parasitoid Eretmocerus mundus Mercet (Hymenoptera: Aphelinidae) and the predators Macrolophus melanotoma (Wagner) and M. pygmaeus (Rambur) (Hemiptera: Miridae), are considered to be important natural enemies of B. tabaci (Karut et al., 2016). In addition, there are many predatory mites, especially those belonging to family Phytoseiidae (Şekeroglu \& Kazak, 1993; Attia et al., 2013), which have been released against T. urticae. With respect to our results, the expectation is that both of these predators can be used as biological control agents of whiteflies and two spotted mites as they are likely to mainly attack their eggs. The reproduction and foraging abilities of these predators when attacking the above mentioned pests have not been extensively investigated. In addition, these experiments were done in the laboratory in small arenas that are very different from natural conditions. Thus, further studies regarding the biological parameters and behavioural responses of these predators when attacking these preys are needed in order to clearly understand their potential capacity in terms of biological control.

ACKNOWLEDGEMENTS. We are grateful to A. Biondi (Department of Agriculture, Food and Environment of the University of Catania, Italy) for reading and editing the manuscript.

\section{REFERENCES}

Alvarado P., Baltà O. \& Alomar O. 1997: Efficiency of four Heteroptera as predators of Aphis gossypii and Macrosiphum euphorbiae (Hom.: Aphididae). - Entomophaga 42: 215-226.

ANDOw D.A. 1990: Population dynamics of an insect herbivore in simple and diverse habitats. - Ecology 71: 1006-1017.

Arnó J., Roig J. \& Riudavets J. 2008: Evaluation of Orius majusculus and O. laevigatus as predators of Bemisa tabaci and estimation of their prey preference. - Biol. Contr. 44: 1-6.

Aslan I., ÖZBeK H., ÇALMașur Ö. \& ŞAhIN F. 2004: Toxicity of essential oil vapours to two greenhouse pests, Tetranychus urticae Koch and Bemisia tabaci Genn. - Industr. Crops Prod. 19: $167-173$.

Attia S., Grissa K.L., Lognay G., Bitume E., Hance T. \& MailLEUX A.C. 2013: A review of the major biological approaches to control the worldwide pest Tetranychus urticae (Acari: Tetranychidae) with special reference to natural pesticides: Biological approaches to control Tetranychus urticae. - J. Pest. Sci. 86: 361-386.

Banihashemi S., Hosseini M.R., Golizadeh H. \& Sankaran S. 2017: Critical success factors (CSFs) for integration of sustainability into construction project management practices in developing countries. - Int. J. Proj. Manag. 35: 1103-1119.

Biondi A., Desneux N., Siscaro G. \& Zappalà L. 2012: Using organic-certified rather than synthetic pesticides may not be safer for biological control agents: Selectivity and side effects of 14 pesticides on the predator Orius laevigatus. - Chemosphere 87: 803-812.

Bostanian N.J., Trudeau M. \& Lasnier J. 2003: Management of the two-spotted spider mite, Tetranychus urticae (Acari: Tetranychidae) in eggplant fields. - Phytoprotection 84: 1-8. 
Breene R.G., Meagher R.L., Nordlund D.A. \& Wang Y.T. 1992: Biological control of Bemisia tabaci (Homoptera: Aleyrodidae) in a greenhouse using Chrysoperla rufilabris (Neuroptera: Chrysopidae). - Biol. Contr. 2: 9-14.

Calvo F.J., Bolckmans K. \& Belda J.E. 2009: Development of a biological control-based integrated pest management method for Bemisia tabaci for protected sweet pepper crops. - Entomol. Exp. Appl. 133: 9-18.

Cedola C.V., Sanchez N.E. \& Lilijesthrom G.G. 2001: Effect of tomato leaf hairness on functioanl and numerical response of Neoseiulus californicus (Acari: Phytoseiidae). - Exp. Appl. Acarol. 25: 819-831.

Chambers R.J., Long S. \& Helyer N.L. 1993: Effectiveness of Orius laevigatus (Hem.: Anthocoridae) for the Control of Frankliniella occidentalis on cucumber and pepper in the UK. - Biocontr. Sci. Technol. 3: 295-307.

Cocuzza G.E., De Clerce P., Van De Veire M., De Cock A., DeGHEELE D. \& VACANTE V. 1997: Reproduction of Orius laevigatus and Orius albidipennis on pollen and Ephestia kuehniella eggs. - Entomol. Exp. Appl. 82: 101-104.

Coll M. \& Ridgway R.L. 1995: Functional and numerical responses of Orius insidiosus (Heteroptera: Anthocoridae) to its prey in different vegetable crops. - Ann. Entomol. Soc. Am. 88: $732-738$.

Cook D.F., Houlding B.J., Steiner E.C., Hardie D.C. \& Postle A.C. 1996: The native anthocorid bug (Orius armatus) as a field predator of Frankliniella occidentalis in Western Australia. - Acta Hortic. 431: 507-512.

Cоте K.W. 2001: Using Selected Acaricides to Manipulate Tetranychus urticae Koch Populations in Order to Enhance Biological Control Provided by Phytoseiid Mites. MSc Thesis, Virginia Polytechnical Institute and State University, Blacksburg, VA, $106 \mathrm{pp}$.

De Clerce P., Mohaghegh J. \& Tirry L. 2000: Effect of host plant on the functional response of the predator Podisus nigrispinus (Heteroptera: Pentatomidae). — Biol. Contr. 18: 65-70.

Denholm I., Cahill M., Dennehy T.J. \& Horowitz A.R. 1998: Challenges with managing insecticide resistance in agricultural pests, exemplified by the whitefly Bemisia tabaci. — Philos. Trans. R. Soc. (B) 353: 1757-1767.

Drobnjaković T., Marčić D., Prijović M., Perić P., Milenković S \& BošKović J. 2016: Life history traits and population growth of Encarsia formosa Gahan (Hymenoptera: Aphelinidae) local population from Serbia. - Entomol. Gen. 35: 281-295.

Fathi S.A.A. \& Nouri-Ganbalani G. 2010: Assessing the potential for biological control of potato field pests in Ardabil, Iran: Functional responses of Orius niger (Wolf.) and O. minutus (L.) (Hemiptera: Anthocoridae). - J. Pest. Sci. 83: 47-52.

Gerling D., Alomar Ò. \& Arnó J. 2001: Biological control of Bemisia tabaci using predators and parasitoids. - Crop Prot. 20: 779-799.

Gigon V., Camps C. \& Le Corff J. 2016: Biological control of Tetranychus urticae by Phytoseiulus macropilis and Macrolophus pygmaeus in tomato greenhouses. - Exp. Appl. Acarol. 68: $55-70$.

Gitonga L.M., Overholt W.A., Löhr B., Magambo J.K. \& MuEKe J.M. 2002: Functional response of Orius albidipennis (Hemiptera: Anthocoridae) to Megalurothrips sjostedti (Thysanoptera: Thripidae). - Biol. Contr. 24: 1-6.

Heitmans W.R.B., OvermeER W.P.J. \& VAN DER GeEst L.P.S. 1986: The role of Orius vicinus Ribaut (Heteroptera; Anthocoridae) as a predator of phytophagous and predacious mites in a Dutch orchard. — J. Appl. Entomol. 102: 391-402.
Helle W. \& Sabelis M.W. 1985: Spider Mites. Their Biology, Natural Enemies and Control. Vol. 1. Elsevier, Amsterdam, part A: xviii + 406 pp., part B: xviii + 458 pp.

Holling C.S. 1959: Some characteristics of simple types of predation and parasitism. - Can. Entomol. 91: 385-398.

Houck M.A. \& Strauss R.E. 1985: The comparative study of functional responses: Experimental design and statistical interpretation. - Can. Entomol. 117: 617-629.

IBM CORP. 2015: SPSS Statistics for Macintosh. IBM Corp Released 2015.

Jalalizand A., Karimy A., Ashouri A., Hosseini M. \& Golparvar A.R. 2012: Effect of host plant morphological features on functional response of Orius albidipennis (Hemiptera: Anthocoridae) to Tetranychus urticae (Acari: Tetranychidae). - Res. Crop. 13: 378-384.

JePpson L.R., KeIfer H.H. \& BAKER E.W. 1975: Mites Injurious to Economic Plants. University of California Press, California, $615 \mathrm{pp}$.

Juliano S.A. 2001: Nonliner curve fitting: predation and functional response curves. In Scheiner S.M. \& Gurevitch J. (eds): Design and Analysis of Ecological Experiments. Oxford University Press, Oxford, pp. 178-196.

Karut K., KazAK C., DöKer İ. \& MaliK A.A.Y. 2016: Efficacy of Eretmocerus mundus (Hymenoptera: Aphelinidae) and Macrolophus melanotoma aganist Bemisia tabaci (Hemiptera: Miridae, Aleyrodidae) in protected tomato. - Turkish J. Entomol. 40: 87-96.

KNOwLes C.O. 1997: Mechanisms of resistance to acaricides. In: Molecular Mechanisms of Resistance to Agrochemicals. Springer, Berlin, Heidelberg, pp. 57-77.

LatTin J.D. 2002: Bionomics of the Anthocoridae. - Annu. Rev. Entomol. 44: 207-231.

Leeuwen T. van, Vontas J., Tsagkarakou A., Dermauw W. \& TIRRY L. 2010: Acaricide resistance mechanisms in the twospotted spider mite Tetranychus urticae and other important Acari: A review. — Insect Biochem. Mol. Biol. 40: 563-572.

Lester P.J., Thistlewood H.M.A. \& Harmsen R. 2000: Some effects of pre-release host-plant on the biological control of Panonychus ulmi by the predatory mite Amblyseius fallacis. Exp. Appl. Acarol. 24: 19-33.

Liu P., Jia W., Zheng X., Zhang L., Sangbaramou R., Tan S., Liu Y. \& SHI W. 2018: Predation functional response and life table parameters of Orius sauteri (Hemiptera: Anthocoridae) feeding on Megalurothrips usitatus (Thysanoptera: Thripidae). - Fla Entomol. 101: 254-260.

Lopez-Avila A. 1986: Taxonomy and biology. In Cock M.J.W. (ed.): Bemisia tabaci - A Literature Survey on the Cotton Whitefly with an Annotated Bibliography. C.A.B. International, Institute of Biological Control, Silwood Park, pp. 3-11.

Madadi H., Enkegaard A., Brodsgaard H.F., Kharrazi-Pakdel A., Mohaghegh J. \& Ashouri A. 2007: Host plant effects on the functional response of Neoseiulus cucumeris to onion thrips larvae. - J. Appl. Entomol. 131: 728-733.

Montserrat M., Albajes R. \& Castañé C. 2000: Functional response of four heteropteran predators preying on greenhouse whitefly (Homoptera: Aleyrodidae) and western flower thrips (Thysanoptera: Thripidae). — Environ. Entomol. 29: 10751082.

NACHMAN G. \& ZeMEK R. 2002: Interactions in a tritrophic acarine predator-prey metapopulation system IV: Effects of host plant condition on Tetranychus urticae (Acari: Tetranychidae). Exp. Appl. Acarol. 26: 27-42.

ÖNDER F. 1982: Taxonomic and Faunistic Studies on the Anthocoridae (Heteroptera) Family in Turkey. Ege University, Faculty of Agriculture, Bornova, İzmir, 159 pp. [in Turkish]. 
Pehlivan S. \& Atakan E. 2017: Some biological parameters of Orius niger (Wolff, 1811) (Hemiptera: Anthocoridae) under outdoor conditions in Turkey. - Turkish J. Entomol. 41: 231231.

Pehlivan S. \& Atakan E. 2020: Distribution and seasonal abundance of predatory bugs, Orius spp. (Hemiptera: Anthocoridae) in Adana Province, Turkey. - Turkish J. Entomol. 44: 57-69.

Péricart J. 1972: Hémiptères Anthocoridae, Cimicidae, Microphysidae de l'Ouest Paléarctique. Faune de l'Europe et du Bassin Méditerranéen. Masson, Paris, 402 pp.

Pervez A. \& Omkar 2006: Ecology and biological control application of multicoloured Asian ladybird, Harmonia axyridis: A review. - Biocontr. Sci. Technol. 16: 111-128.

Queiroz O.S., Ramos R.S., GontiJo L.M. \& Picanço M.C. 2015: Functional response of three species of predatory pirate bugs attacking eggs of Tuta absoluta (Lepidoptera: Gelechiidae). Environ. Entomol. 44: 246-251.

RAWORTH D.A. 1990: Predators associated with the twospotted spider mite, Tetranychus urticae, on strawberry at Abbotsford, B.C., and development of non-chemical mite control. - J. Entomol. Soc. Br. Columb. 87: 59-67.

RiudAVETS J. \& CASTAÑé C. 1998: Identification and evaluation of native predators of Frankliniella occidentalis (Thysanoptera: Thripidae) in the Mediterranean. - Environ. Entomol. 27: 86-93.

ROGERS D. 1972: Random search and insect population models. - J. Anim. Ecol. 41: 369-383.

Roy M., Brodeur J. \& Cloutier C. 2005: Seasonal activity of the spider mite predators Stethorus punctillum (Coleoptera: Coccinellidae) and Neoseiulus fallacis (Acarina: Phytoseiidae) in raspberry, two predators of Tetranychus mcdanieli (Acarina: Tetranychidae). - Biol. Contr. 34: 47-57.

Rutledge C.E. \& O’Neil R.J. 2005: Orius insidiosus (Say) as a predator of the soybean aphid, Aphis glycines Matsumura. Biol. Contr. 33: 56-64.
Salehi Z., Yarahmadi F., Rasekh A. \& Sohani N.Z. 2016: Functional responses of Orius albidipennis Reuter (Hemiptera, Anthocoridae) to Tuta absoluta Meyrick (Lepidoptera, Gelechiidae) on two tomato cultivars with different leaf morphological characteristics. - Entomol. Gener. 36: 127-136.

Şereroglu E. \& KaZaK C. 1993: First record of Phytoseiulus persimilis (Acari: Phytoseiidae) in Turkey. - Entomophaga 38: 343-345.

Shahpouri A., Yarahmadi F. \& Zandi Sohani N. 2019: Functional response of the predatory species Orius albidipennis Reuter (Hemiptera: Anthocoridae) to two life stages of Bemisia tabaci (Genn.) (Hemiptera: Aleyrodidae). - Egypt. J. Biol. Pest Contr. 29: 14, 6 pp.

Trexler J.C., McCulloch C.E. \& Travis J. 1988: How can functional response best be determined? - Oecologia 76: 206-214.

Tuan S.J., Yang C.M., Chung Y.T., Lai W.H., Ding H.Y., Saska P. \& PENG S.C. 2016: Comparison of demographic parameters and predation rates of Orius strigicollis (Hemiptera: Anthocoridae) fed on eggs of Tetranychus urticae (Acari: Tetranychidae) and Cadra cautella (Lepidoptera: Pyralidae). - J. Econ. Entomol. 109: $1529-1538$.

Venzon M., Janssen A. \& Sabelis M.W. 2002: Prey preference and reproductive success of the generalist predator Orius laevigatus. - Oikos 97: 116-124.

Wearing C.H. \& Colhoun K. 1999: Development of Orius vicinus (Ribaut) (Heteroptera: Anthocoridae) on different prey. Biocontr. Sci. Technol. 9: 327-334.

XIAO Y. \& FadAmiRo H.Y. 2010: Functional responses and preystage preferences of three species of predacious mites (Acari: Phytoseiidae) on citrus red mite, Panonychus citri (Acari: Tetranychidae). - Biol. Contr. 53: 345-352.

Received August 27, 2019; revised and accepted January 14, 2020 Published online January 30, 2020 